\title{
A Bioremediation Study of Raw and Treated Crude Petroleum Oil Polluted Soil with Aspergillus niger and Pseudomonas aeruginosa
}

\author{
Modupe Elizabeth Ojewumi i" Ejemen Valentina Anenih', \\ Olugbenga Samson Taiwo', Bosede Temitope Adekeye², \\ Olugbenga Olufemi Awolu ${ }^{3}$, Emmanuel Omotayo Ojewumi ${ }^{3}$
}

\author{
1 Chemical Engineering Department, Covenant University, P.M.B 1023, Canaan Land, Sango, Ogun State, \\ Nigeria \\ 2 Microbiology Department, Covenant University, P.M.B 1023, Canaan Land, Sango, Ogun State, Nigeria \\ 3 Department of Food Science and Technology, Federal University of Technology, P.M.B. 704, Akure, Ondo \\ State, Nigeria \\ * Corresponding author's e-mail: modupe.ojewumi@covenantuniversity.edu.ng
}

\begin{abstract}
This study was conducted to investigate the degree of bioremediation that would occur in the samples of soil polluted with raw and treated crude petroleum (oil) with the aid of Aspergillus niger (fungi) and Pseudomonas aeruginosa (bacteria). This was achieved by monitoring the Organic carbon content in the soil over 45 days and $\mathrm{pH}$ over 25 days. Four systems of $500 \mathrm{~g}$ soil were polluted with $40 \mathrm{~g}$ treated crude petroleum, while four systems were contaminated with $40 \mathrm{~g}$ raw crude petroleum. The eight systems were labeled accordingly. Two systems for raw crude control and treated crude control (RCC and TCC) were left as control, two systems for raw crude Aspergillus niger and treated crude Aspergillus niger (RCA and TCA) were treated with Aspergillus niger only, two systems for raw crude Pseudomonas aeruginosa and treated crude Pseudomonas aeruginosa (RCP and TCP) were treated with Pseudomonas aeruginosa only and the last two systems for raw crude Aspergillus niger and Pseudomonas aeruginosa (RCAP and TCAP) were treated with both Pseudomonas aeruginosa and Aspergillus niger. At the end of the bioremediation period, the results obtained showed that the $\mathrm{pH}$ was not particularly a solid parameter to estimate the degree of bioremediation. This is because a proper trend in the results obtained could not be determined. Additionally, it was observed that Aspergillus niger (fungi) and Pseudomonas aeruginosa (bacteria) alone and separate remediate raw crude polluted soil better than treated crude polluted soil. This was determined by the TOC (Total Organic Carbon) values on the $45^{\text {th }}$ day of the experiment.
\end{abstract}

Keyword: bioremediation, Aspergillus niger, Pseudomonas aeruginosa, pollution

\section{INTRODUCTION}

Since the nineteenth century, petroleum has been utilized for a very long time for power generation and lubrication. A greater interest in the natural resource and its by-products was created. The processes involved in obtaining the crude oil and converting it into more useful products usually causes contamination problems. These pollution problems can be minimized, yet not completely eliminated and hence bring on several issues for the environment [Pala et al., 2006]. A number of studies of oil spill bioremedia- tion on marine shore lines have been conducted [Efeovbokhan et al., 2001; Facundo et al., 2001; Jelena et al., 2008; Rittmann and McCarty, 2001; Pao-Wen et al., 2011]. One of the major concerns of the oil industry today is how to improve the recovery of large percentage of oil remaining unrecovered in the old and new depleted producing fields [Ojewumi et al., 2017]. The famous bioremediation is an amazing spill clean-up technique in which the normal degrading ability of microorganisms is harnessed for the degradation and decrease of the harmful substances that pollute the environment. Some of the substances in this 
category include petroleum subsidiaries, aliphatic and sweet-smelling hydrocarbons, mechanical solvents, pesticides and metals [Che, 2002]. The microbial degradation is the major and ultimate natural mechanisms by which one can clean up the petroleum hydrocarbon pollutants from the environment [Atlas and Bragg, 2009]. Of all the technologies and methods for cleaning up oil spills on soils that have been researched in the recent past, bioremediation has come out as the most desirable approach due to its low cost and ability to hinder the formation and accumulation of contaminants [Margesin and Schinner, 2001]. Among the many techniques employed to decontaminate the affected sites, in situ bioremediation using indigenous microorganisms is by far the most widely used [Nwinyi, 2010; Ojewumi et al., 2017]. Bioremediation is a term used to describe a process that takes advantage of the natural ability of a microorganism to degrade toxic waste. This technique is very effective in cleaning up the petroleum hydrocarbon pollution. It is a modern technique, whereby the natural degrading ability of microorganisms is used to reduce the concentration and/or toxicity of wide range chemical substances that are released into the environment. Some of these compounds may include petroleum derivatives, aliphatic and aromatic hydrocarbons, industrial solvents, pesticides and metals [Jelena et al., 2008]. The remediation process in question works by stimulating the microbes that occur naturally in the environment to degrade the organic wastes found in soil and groundwater. The microorganisms that degrade crude oil use the hydrocarbon breakdown as their source of chemical energy. Some microorganisms can naturally degrade petroleum hydrocarbons by utilizing the carbon within it to survive. The hydrocarbons that exist in crude oil serve as substrates for the microorganisms. Normally, without any external enhancement or intervention, as soon as an oil spill occurs there is a rise in the population of microbes that degrade the hydrocarbons within the ecosystem.

Aspergillus niger has found wide application in waste management and bio-transformations. The fungus is most commonly found in mesophilic environments, such as decaying vegetation or soil and plants [Schuster et al., 2002; Das and Mukherjee, 2007]. Filamentous fungi play an important role in degrading hydrocarbons by producing capable enzymes. This is as a result of their aggressive growth, greater biomass production and extensive hyphal growth in soil. Fungi offer a potential for biodegradation technology [Nilanjana and Preethy, 2011]. The fungi cause a disease called black mould on some fruits and vegetables like grapes, apricots and peanuts [Samson et al., 2001].

Pseudomonas aeruginosa as crude oil degrading bacteria is a gram-negative, rod-shaped bacterium that has an incredible nutritional versatility. It is a rod about 1-5 $\mu \mathrm{m}$ long and $0.5-1.0 \mu \mathrm{m}$ wide. Pseudomonas aeruginosa, as well as many other Pseudomonas, can degrade aromatic hydrocarbons and can break down toluene, the simplest form of methylbenzene [Johson and Olsen, 1997]. Naturally, it is found in such environments as soil, water, humans, animals, plants, sewage, and hospitals [Lederberg, 2000]. The factors that are necessary for the microbial growth are temperature, oxygen, $\mathrm{pH}$, as well as the content of nitrogen and phosphorus. The degree and rate of biodegradation are influenced by the type of soil in which the process occurs [Ritmann and McCarty, 2001]. The main microorganisms that degrade petroleum hydrocarbons are bacteria and fungi. Using microorganisms for hydrocarbon degradation has proven to be the most environmentally-friendly oil spill clean-up method [Facundo et al., 2001; Chen et al., 2007]. Specifically, fungi offer a potential for biodegradation technology [Van et al., 2003].

The decomposition of dead plants and animals causes natural occurrence of carbon in soil. The range organic carbon found in soils cuts across freshly deposited litter like leaves, twigs, branches and highly decomposed forms such as humus. Apart from the carbon that occurs in soil naturally, the anthropogenic activities are also sources of carbon in soil, derived as a result of contamination through oil spills. These spills pollute the environment and invariably increase the total carbon content present in the soil or sediment [Schuster et al., 2002]. The Total Organic Carbon is a measure of one of the chemical components of organic matter that is used as a reliable indicator of its presence in a soil or sediment. The determination of the soil organic carbon is based on the Walkley-Black chromic acid [Van et al., 2003] oxidation method. Estimating the Total Organic Carbon is used to determine the amount of hydrocarbons in the soil since they largely comprise carbon.

The term $\mathrm{pH}$ generally refers to the degree of acidity or alkalinity of a substance. Soil $\mathrm{pH}$ is a very important variable in soils, because it con- 
trols many chemical processes that take place. It specifically affects the plant nutrient availability by controlling the chemical forms of the nutrient. The optimum $\mathrm{pH}$ range for most plants is between 5.5 and 7.0. The closer to neutrality the $\mathrm{pH}$ of a soil sample is, the better the soil. An effective bioremediation would ensure that the $\mathrm{pH}$ of the polluted soil would return to its initial value before the pollution occurred. The changes in the $\mathrm{pH}$ level of the soil may be caused by oil spills. Hence, a close monitoring of the $\mathrm{pH}$ during a remediation process would be a determinant to how effective the process is.

This research focuses on studying the degree of bioremediation in raw crude oil polluted soil and treated crude oil polluted soil using Aspergillus niger and Pseudomonas aeruginosa as potential hydrocarbon degraders. This study shows the effect of the bioremediation of crude oil polluted soil with each microorganism individually, as well as both microbes in a mixed microbial consortium. In order to achieve this, the organic content in the soil over the remediation period as well as the soil $\mathrm{pH}$ would be monitored.

\section{MATERIALS AND METHOD}

\section{Soil sample}

The loamy soil samples used to simulate the crude oil onshore spill were obtained from Covenant University Farms, Canaan land Ota, Nigeria. This soil was collected from the surface layer, about 20 to $30 \mathrm{~cm}$ below the land surface. The soil sample was air dried to get rid of the excess moisture, as soil was collected during the heavy rains. The soil was homogenized and stored in a black plastic bucket at room temperature. The dried soil was characterized for the physicochemical and microbial parameters, according to the standard methods. The raw and treated crude oil samples (Escravos light) used for this study were obtained from Chevron Nigeria Limited, Delta state Nigeria in December 2015.

\section{Preparation of microorganisms}

The fungi (Aspergillus niger) and bacteria (Pseudomonas aeruginosa) used for this study were cultured in the Microbiology Department of Covenant University and prepared according to [Ojewumi et al., 2016; Ojewumi et al., 2018].

\section{Determination of $\mathrm{pH}$}

The $\mathrm{pH}$ of the non-polluted soil sample was determined as well as the $\mathrm{pH}$ of the raw and treated crude petroleum (oil) samples of each system, one week after pollution just before the inoculation of the micro-organisms. The $\mathrm{pH}$ was subsequently determined at 5 day intervals, as the remediation process was underway, using a digital pH meter (Model: Jenway M50/Rev model CE $350 \mathrm{EU}$ ) in a ratio 1:1 soil sample solution in distilled water. The $\mathrm{pH}$ meter was calibrated using phthalate buffer solution with a $\mathrm{pH}$ of 4.0 and phosphate buffer solution with $\mathrm{pH}$ of 7.0. $5 \mathrm{~g}$ of the soil samples were mixed with $5 \mathrm{ml}$ of distilled water and stirred very well, after which mixture was allowed to stand for 30 minutes. The electrode of a $\mathrm{pH}$ meter was put into slurry of the soilwater mixture and the $\mathrm{pH}$ of the soil was read off.

\section{Determination of total organic carbon (TOC)}

This parameter was measured in the nonpolluted soil, before the commencement of the remediation process. In order to determine the organic carbon, the Walkey-Black Wet Dichromate method according was used. The required reagents were $0.5 \mathrm{M}$ Ferrous Sulphate solution, 1.0M Potassium Dichromate solution, concentrated $\mathrm{H}_{2} \mathrm{SO}_{4}(98 \%)$ and Ferroin indicator.

$1 \mathrm{~g}$ of the soil sample from a system was weighed and put into a $250 \mathrm{ml}$ conical flask. $10 \mathrm{ml}$ of the $1.0 \mathrm{M}$ Potassium Dichromate solution was added to the conical flask. $20 \mathrm{ml}$ of concentrated $\mathrm{H}_{2} \mathrm{SO}_{4}$ was also added to the flask under a fume hood and stirred gently. It was left under the fume hood for 5 minutes after which it was brought out. Distilled water was then added to the $125 \mathrm{~mL}$ mark, mixed vigorously by swirling and allowed to stand for 30 minutes. After the stipulated time, 3 drops of Ferroin indicator was added. This was then titrated with $0.5 \mathrm{M}$ ferrous sulphate solution. The titration was carried out twice for each sample and the average volume of the acid used was recorded. This test was carried out on the non-polluted soil sample, the soil samples from all the systems after pollution just before inoculation, and each soil sample at 5 day intervals during the remediation process.

In order to calculate the percentage TOC, the percentage of easily oxidized carbon was calculated first. The amount of organic matter was also calculated once the total organic carbon was known. The calculation of organic matter as- 
sumes that $77 \%$ of the organic carbon is oxidized by the method and that soil organic matter (SOM) contains $58 \% \mathrm{C}$.

Percent of easily oxidizable carbon (EOC) is thus calculated in the following way:

$$
\% \mathrm{EOC}=\frac{(\mathrm{B}-\mathrm{S}) * \mathrm{M} * 12}{m * 4000} * 100 \%
$$

where: $B$ is the volume of ferrous solution used in the blank titration in $\mathrm{ml}$;

$S$ is the volume of ferrous solution used in the sample titration in $\mathrm{ml}$;

$m$ is the mass of the sample in grams used in the analysis which is $1 \mathrm{~g}$ in this case;

$M$ is the molarity of the ferrous sulphate solution $=0.5 \mathrm{M}$

$12 / 4000=$ milliequivalent weight of carbon in grams.

Percebt of TOC can be obtained from \%EOC by applying a correction factor.

$$
\begin{gathered}
\% \mathrm{TOC}=\frac{\% \mathrm{EOC}}{0.77} \\
\% \mathrm{SOM}=\frac{\% \mathrm{TOC} * 1.72}{0.58}
\end{gathered}
$$

\section{RESULTS AND DISCUSSION}

\section{Organic Carbon}

Blank titration of the acidic dichromate with ferrous sulphate solution was performed at the beginning of the batch analysis using the same procedure with no soil added (Table 1).

Average Volume of Ferrous Sulphate used in Standardization,

$$
\mathrm{B}=\frac{19.40+20.00+19.60}{3}
$$

The collated table of average titre values of ferrous sulphate solution used to oxidize the soil samples mixed with potassium dichromate solution over the period of experimentation as well as the $\% \mathrm{EOC}, \% \mathrm{TOC}$ and $\% \mathrm{OM}$ is shown (Table 2). The graphs 1-8 shows \%EOC, \%TOC and \%SOM against time for each system over the course of 45 days.

\section{Total organic carbon}

Table 2 shows the values obtained for the easily oxidizable carbon, total organic carbon and organic matter in the soil. The most important parameter is the total organic carbon (TOC). At the start of the experiment (day 0), some of the samples had equal organic carbon content because no microbial degradation had occurred. For all the systems polluted with raw crude petroleum (RCA, RCP, RCAP, and RCC) a Total Organic Carbon of $2.057 \%$ was recorded. The systems polluted with treated crude petroleum (TCA, TCP, TCAP and TCC) had a Total Organic Carbon content of $2.8461 \%$ as shown in the table. This result showed that the treated crude oil systems had more carbon content on the average at the start of the experiment. Subsequently, the Total Organic Carbon for all the systems spiked on the $5^{\text {th }}$ day. This was probably due to the fact that the carbon content originally in the soil was properly blended with the crude oil (petroleum), leading to an increase in the Total Organic Carbon. Between the $5^{\text {th }}$ and $10^{\text {th }}$ day, there was a commendable reduction in the Total Organic Carbon of all the systems. Some of the soil samples experienced a very drastic decrease in TOC within this period of time. A typical example can be seen in the system RCP in which the TOC decreased from $3.752 \%$ to $2.466 \%$. In contrast, other systems experienced just a minute decrease within this period of time. Additionally, it was observed that some of the systems treated with Aspergillus niger developed a whitish substance (which appeared to be mould growth) on them. Approximately on the $20^{\text {th }}$ day, it was observed that the systems began to produce a foul odour that resembled the smell of decomposing organic waste.

At the end of 45 days of experimenting, the TOC of majority of the systems had decreased to less than $1 \%$, as shown in table. The system TCAP had residual TOC of less than $0 \%(-1.332 \%)$. These values came about as a result of the values obtained from titration. At this point, the volume of acid used to titrate each soil sample was greater than the volume of the blank titre, hence the

Table 1. Blank titre obtained from standardization

\begin{tabular}{|l|c|c|c|}
\hline \multicolumn{1}{|c|}{ Blank titre obtained from standardization } & Blank 1 & Blank 2 & Blank 3 \\
\hline Initial $(\mathrm{ml})$ & 0.00 & 19.40 & 0.00 \\
\hline Final $(\mathrm{ml})$ & 19.40 & 39.40 & 19.60 \\
\hline Volume used $(\mathrm{ml})$ & 19.40 & 20.00 & 19.60 \\
\hline
\end{tabular}


Table 2. Organic carbon data collation across the 45 days

\begin{tabular}{|c|c|c|c|c|c|c|c|c|c|}
\hline Day & & RCA & TCA & $\mathrm{RCP}$ & TCP & RCAP & TCAP & $\mathrm{RCC}$ & TCC \\
\hline \multirow{4}{*}{ Day 0} & Vol (ml) & 9.1 & 5.05 & 9.1 & 5.05 & 9.1 & 5.05 & 9.1 & 5.05 \\
\hline & $\%$ EOC & 1.58 & 2.19 & 1.58 & 2.19 & 1.58 & 2.19 & 1.58 & 2.19 \\
\hline & $\%$ TOC & 2.06 & 2.85 & 2.06 & 2.85 & 2.06 & 2.85 & 2.06 & 2.85 \\
\hline & $\%$ OM & 6.10 & 8.44 & 6.10 & 8.44 & 6.10 & 8.44 & 6.10 & 8.44 \\
\hline \multirow{4}{*}{ Day 5} & Vol (ml) & 2.4 & 6.35 & 0.4 & 1.35 & 5.15 & 5.15 & 2.6 & 3.2 \\
\hline & $\%$ EOC & 2.59 & 1.99 & 2.89 & 2.75 & 2.18 & 2.18 & 2.56 & 2.47 \\
\hline & $\%$ TOC & 3.36 & 2.59 & 3.75 & 3.57 & 2.83 & 2.83 & 3.32 & 3.21 \\
\hline & $\%$ OM & 9.97 & 7.69 & 11.13 & 10.58 & 8.38 & 8.38 & 9.86 & 9.51 \\
\hline \multirow{4}{*}{ Day 10} & Vol (ml) & 5.2 & 6.9 & 7 & 8.55 & 8 & 9.2 & 5.65 & 7.3 \\
\hline & $\%$ EOC & 2.17 & 1.91 & 1.89 & 1.67 & 1.75 & 1.57 & 2.10 & 1.85 \\
\hline & $\%$ TOC & 2.82 & 2.49 & 2.47 & 2.16 & 2.27 & 2.04 & 2.73 & 2.41 \\
\hline & $\%$ OM & 8.35 & 7.37 & 7.31 & 6.41 & 6.74 & 6.04 & 8.09 & 7.14 \\
\hline \multirow{4}{*}{ Day 15} & Vol (ml) & 10.25 & 5.85 & 7.4 & 13 & 10.5 & 12 & 4.2 & 5.6 \\
\hline & $\%$ EOC & 1.41 & 2.07 & 1.84 & 0.99 & 1.37 & 1.15 & 2.32 & 2.11 \\
\hline & $\%$ TOC & 1.83 & 2.67 & 2.39 & 1.30 & 1.78 & 1.49 & 3.01 & 2.74 \\
\hline & $\%$ OM & 5.43 & 7.98 & 7.08 & 3.85 & 5.29 & 4.43 & 8.93 & 8.12 \\
\hline \multirow{4}{*}{ Day 20} & Vol (ml) & 12.3 & 7.8 & 11.5 & 12.7 & 11.7 & 13.6 & 5.4 & 8.3 \\
\hline & $\%$ EOC & 1.10 & 1.78 & 1.22 & 1.04 & 1.19 & 0.91 & 2.14 & 1.70 \\
\hline & $\%$ TOC & 1.43 & 2.31 & 1.59 & 1.36 & 1.55 & 1.18 & 2.78 & 2.21 \\
\hline & $\%$ OM & 4.25 & 6.85 & 4.71 & 4.02 & 4.60 & 3.50 & 8.24 & 6.56 \\
\hline \multirow{4}{*}{ Day 30} & Vol (ml) & 11.8 & 10.2 & 16.4 & 14.2 & 14.8 & 15.6 & 9.7 & 10.8 \\
\hline & $\%$ EOC & 1.18 & 1.42 & 0.49 & 0.82 & 0.73 & 0.61 & 1.49 & 1.34 \\
\hline & $\%$ TOC & 1.53 & 1.84 & 0.64 & 1.06 & 0.947 & 0.79 & 1.94 & 1.74 \\
\hline & $\%$ OM & 4.54 & 5.47 & 1.88 & 3.15 & 2.81 & 2.35 & 5.75 & 5.15 \\
\hline \multirow{4}{*}{ Day 45} & Vol (ml) & 18.4 & 15.7 & 19.4 & 17.05 & 16.9 & 26.5 & 16.3 & 18.7 \\
\hline & $\%$ EOC & 0.19 & 0.59 & 0.05 & 0.39 & 0.414 & -1.03 & 0.51 & 0.14 \\
\hline & $\%$ TOC & 0.25 & 0.77 & 0.06 & 0.51 & 0.54 & -1.33 & 0.66 & 0.19 \\
\hline & \% OM & 0.73 & 2.29 & 0.18 & 1.51 & 1.59 & -3.95 & 1.97 & 0.55 \\
\hline
\end{tabular}

\section{Key:}

TCC Treated Crude Control sample

RCC Raw Crude Control sample

RCA Raw Crude Treated with Aspergillus niger

TCA Treated Crude Treated with Aspergillus niger

RCP Raw Crude Treated with Pseudomonas aeruginosa

TCP Treated Crude Treated with Pseudomonas

negative TOC value. The plots shown in figures 1 to 8 clearly depict the trend in the EOC, TOC and OM. These three curves on each plot were observed to have the same rising and falling trend at each point for each of the systems.

\section{$\mathrm{pH}$}

The $\mathrm{pH}$ of the unpolluted soil was measured and estimated to be 6.81 . The test for the degree of acidity or alkalinity in each of the systems aeruginosa

RCAP Raw Crude Treated with Aspergillus niger and Pseudomonas aeruginosa

TCAP Treated Crude Treated with Aspergillus niger and Pseudomonas aeruginosa

EOC Easily Oxidizable Carbon

TOC Total Organic Carbon

OM Organic Matter

was done at four different times within the first 25 days; the chart is shown in Figure 9. The values obtained were used to plot a simple column chart that shows the $\mathrm{pH}$ range for all 8 systems at four different times within the first 25 days. The $\mathrm{pH}$ of all the soil systems spiked within the first five days to the values above 7.0. The $\mathrm{pH}$ of some systems rose to as high as 7.9 (as seen in RCAP) within the first five days. On average, after the first five days till the $15^{\text {th }}$ day, the $\mathrm{pH}$ of some of the systems decreased with the exception of TCA, 


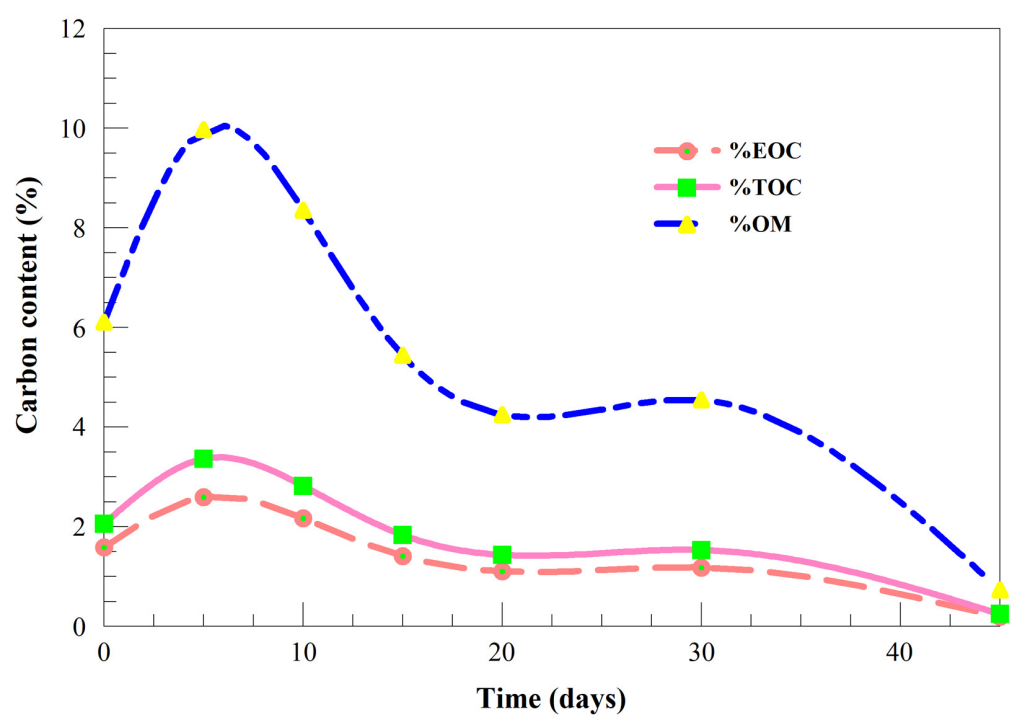

Fig. 1. Carbon content variation for RCA

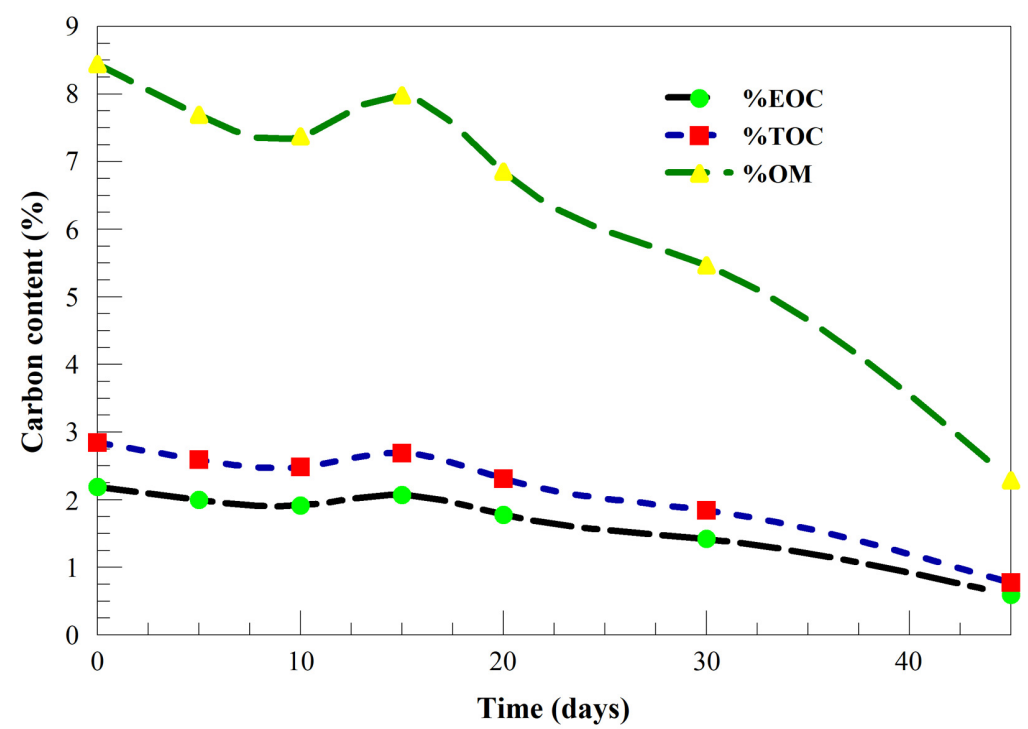

Fig. 2. Carbon content variation for TCA

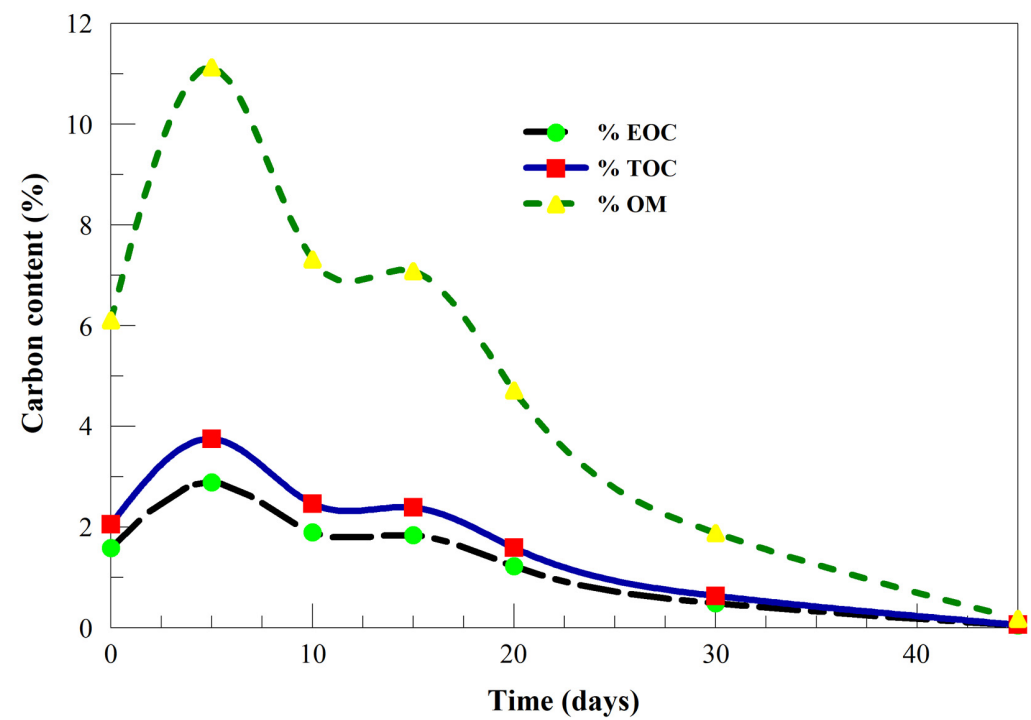

Fig. 3. Carbon content variation for RCP 


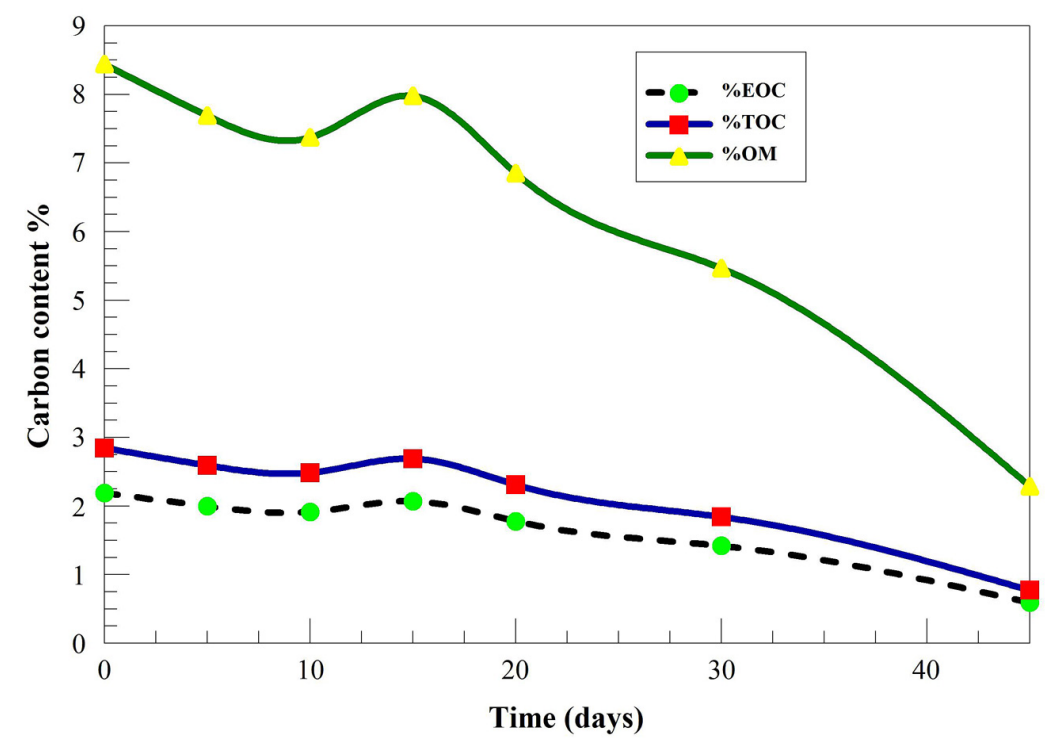

Fig. 4. Carbon content variation for TCP



Fig. 5. Carbon content variation for RCAP

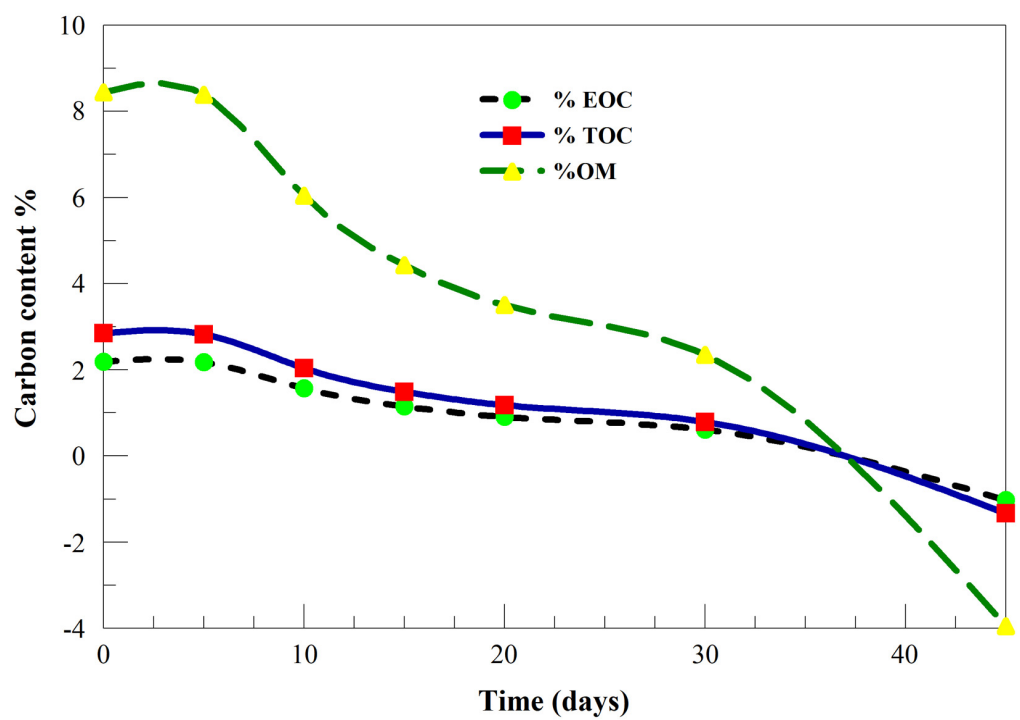

Fig. 6. Carbon content variation for TCAP 


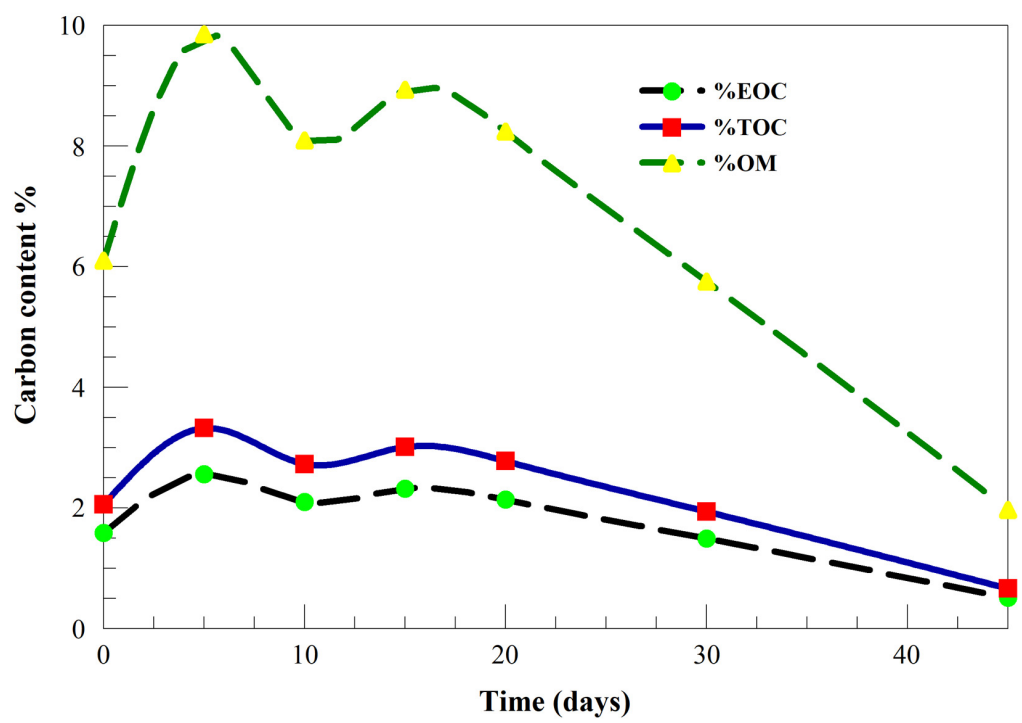

Fig. 7. Carbon content variation for RCC

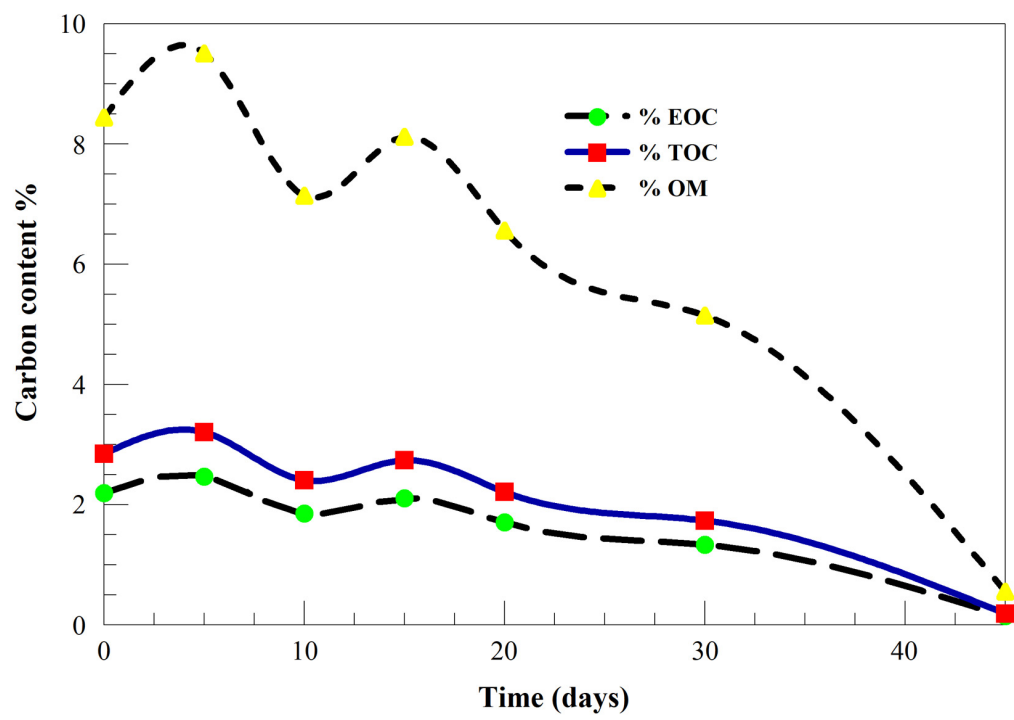

Fig. 8. Carbon content variation for TCC

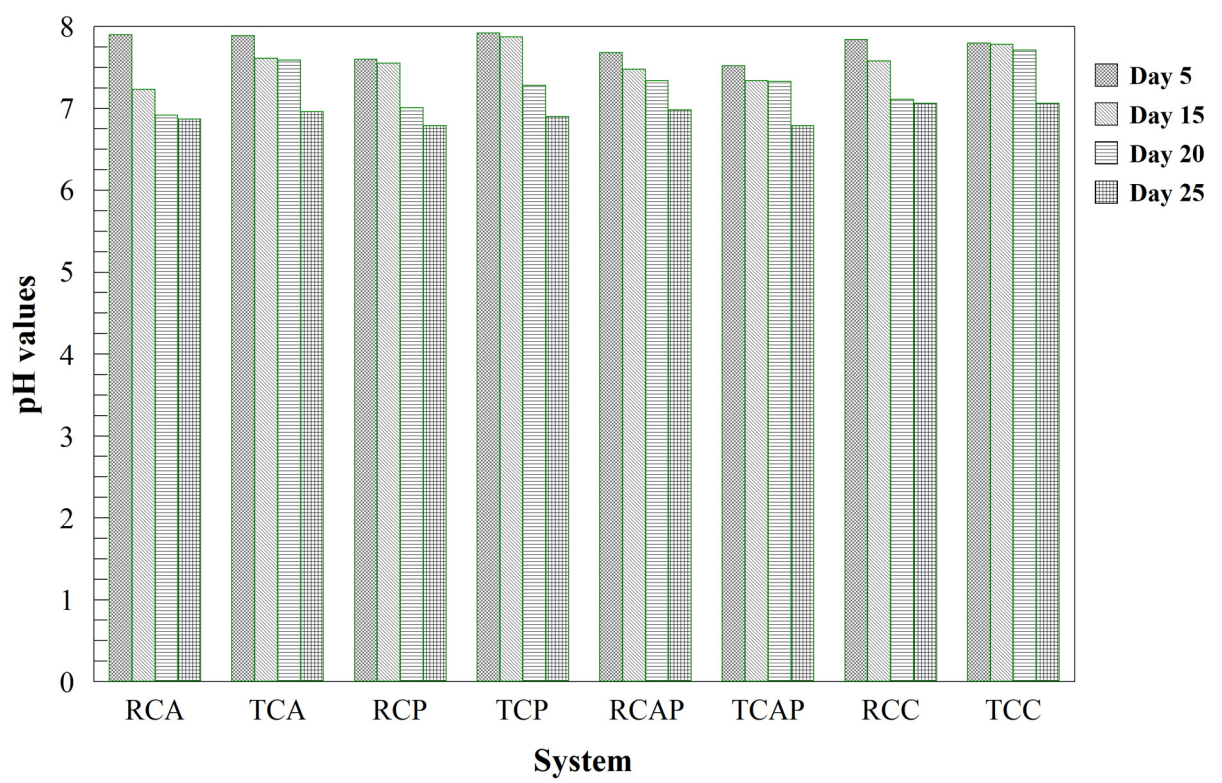

Fig. 9. $\mathrm{pH}$ for all Systems 
TCP, TCAP and TCC. Between the $15^{\text {th }}$ and $20^{\text {th }}$ day, all the $\mathrm{pH}$ values for all systems decreased but there was a fluctuation in the trend in some of the samples. The $25^{\text {th }}$ day showed a major $\mathrm{pH}$ reduction in all the systems. The $\mathrm{pH}$ of all the systems decreased to values below 7.0. This shows that effective remediation had occurred in all the systems, proceeding towards returning the soil samples to the original state of the soil. Around the $25^{\text {th }}$ day, some $\mathrm{pH}$ values fell below the value of the $\mathrm{pH}$ of the unpolluted soil, as seen in RCP 2 (6.56).

\section{CONCLUSIONS}

Using Aspergillus niger alone remediates the raw crude oil polluted soil better than the treated crude oil polluted soil. Therefore, for a spill site polluted with raw crude oil, Aspergillus niger would be a better choice of biostimulant compared to Pseudomonas aeruginosa. The use of Pseudomonas aeruginosa as a biostimulant is more effective in the remediation of the soil polluted with treated crude oil. Therefore, for an oil spill site polluted with treated crude oil from a flow line or even the production platform, $\mathrm{Pseu}$ domonas aeruginosa is a better choice of biostimulant compared to Aspergillus niger. Using both Aspergillus niger and Pseudomonas aeruginosa in combination is generally a better biostimulant compared to using either Aspergillus niger or Pseudomonas aeruginosa alone. This is observed from the biostimulant efficiency and percentage crude oil removal. Generally, the treated crude oil spills remediate faster and to a larger extent than the spills caused by raw crude oil.

The $\mathrm{pH}$ test is not a very good determining factor for remediation level, because the result obtained did not exhibit a distinct trend as a result of fluctuations.

\section{Acknowledgements}

The authors appreciate the partial sponsorship of Covenant University, Ota, Nigeria.

\section{REFERENCES}

1. Atlas R., Bragg J. 2009. Bioremediation of marine oil spills: when and when not - the Exxon Valdez experience. Microbial Biotechnology, 2(2), 213221.
2. Che M.D. 2002. Conservative cost estimaye including investigation and monitoring expenses, soil and ground water remediation confenrence proceeding, Taipei.

3. Chen S.Y., Lu W.B., Wei Y.H., Chen W.M., Chang J.S. 2007. Improved production of biosufactant with newly isolated Pseudomonas aeruginosa S2. Bioresource Technology, 23, 661-666.

4. Das K., Mukherjee A.K. 2007. Crude petroleumoil biodegradation efficiency of Bacillus subtilis and Pseudomonas aeruginosa strains isolated from a petroleum-oil contaminated soil from North-East India. Bioresource Technology, 98(7), 1339-1345.

5. Efeovbokhan V.E., Anawe P., Apeye L., Makinde F.A., Odunmbaku O. 2011. Comparison of the efficiency of sodium nitrate and superphosphate as nutrients in the bioremediation of petroleum hydrocarbon polluted water. American Journal of Scientific and Industrial Research, 2(2), 272-282. doi:10.5251/ajsir.2011.2.2.278.282.

6. Facundo J., Vanessa H., Teresa M. 2001. Biodegradation of diesel oil in soil by a microbial consortium. Water, Air and Soil Pollution, 313-320.

7. Jelena S.M., Beškoski V.P., Mila V.I., Samira A.M., Gordana D., Miroslaw M.V. 2008. Bioremediation of soil heavily contaminated with crude oil and its products: composition of the microbial consortium. Journal of the Serbian Chemical Society, 74(4), 455-460.

8. Lederberg J. 2000. Pseudomonas. Encyclopedia of Microbiology, pp. 876-891.

9. Margesin R., Schinner F. 2001. Bioremediation (natual attenuation and biostimulation) of dieseloil-contaminated soil in an alpine glacier skiing area. Applied and Environmental Miacrobiology, 67, 3127-3133.

10. Nilanjana D., Preethy C. 2001. Microbial Degradation of Petroleum Hydrocarbon Contaminants: An Overview. Biotechnology Research International, Volume 2011, Article ID 941810, 13 pages. doi:10.4061/2011/941810

11. Nwinyi O. 2010. Degradation of Askarel (PCB Blend) by Indigenous Aerobic Bacteria Isolates from Dumpsites in Ore, Ondo State.Nigeria. Australian Journal of Basic and Applied Sciences, 4 (8). 3938-3948.

12. Ojewumi M.E., Obielue B.I., Emetere M.E., Awolu, O.O., Ojewumi, E.O. 2018. Alkaline PreTreatment and Enzymatic Hydrolysis of Waste Papers to Fermentable Sugar. Journal of Ecological Engineering, 19(1), 211-217. https://doi. org/10.12911/22998993/79404.

13. Ojewumi M.E., Emetere M.E., Babatunde D.E., Okeniyi, J.O. 2017. In Situ Bioremediation of Crude Petroleum Oil Polluted Soil Using Mathematical Experimentation. International Journal of 
Chemical Engineering. Volume 2017, Article ID 5184760.

14. Pala M., De Carvalho D., Pinto J.C., Sant Anna Jr G.L. 2006. A suitable model to describe bioremediation of a petroleum-contaminated soil. Journal of International Biodeterioration \& Biodegradation, 58(6), 254-260.

15. Pao-Wen G.L., Tsung C.C., Liang-Ming W., ChunHsuan K., Po-Tseng P., Sheng-Shung C. 2011. Bioremediation of petroleum hydrocarbon contaminated soil: Effects of strategies and microbial community shift. International Biodeterioration and Biodegradation, 65(2011), 1119-1127.

16. Rittmann B.E., McCarty P.L. 2001. Enviromental Biotechnology: Principles and Applications. New York: McGraw-Hill.
17. Robert M., Stephen J.A. 2003. Biodegradation of fuel oil under laboratory and arctic marine conditions. Spill Science and Technology Bulletin, 297-302.

18. Samson R., Houbraken J., Summerbell R., Flannigan B. 2001. Common and important species of fungi and actinomycetes in indoor environments: Microogranisms in Home and Indoor Work Environments.

19. Schuster E., Dunn-Coleman N., Frisvad J., Van Dijck P. 2001. On the safety of Aspergillus niger - a review. Applied Microbiology and Biotechnology, 59, 426-435.

20. Van Hamme J., Singh A., Owen W.P. 2003. Microbiology and Molecular Biology Review, 503-549. 